\title{
The Effect of Different Dielectric Constant on Same Microstrip Patch Antenna Design
}

\author{
Zeeshan Alam, S.K.Sriwas, Atul Kumar Dwivedi, Yatharth Shankar Misra
}

\begin{abstract}
This paper demonstrate the effect of textile material (Jeans) on U.W.B. we all familiar with the information that U.W.B is in between 3.1 to $10.6 \mathrm{GHz}$, That is assigned by the society of F.C.C (Federal Communication Commission) in 2002.The convoluted design present in this paper, It has designing frequency of $2.4 \mathrm{GHz} \&$ we have used IE3D software for simulation. The bandwidth, gain, directivity \& efficiency of textile antenna are $109 \%, 6.69 \mathrm{dBi}, 6.7 \mathrm{dBi}, 99.6 \%$ respectively and bandwidth, gain, directivity, efficiency of reference antenna are $103 \%, 7.21 \mathrm{dBi}, 7.28 \mathrm{dBi}, 99.5 \%$ respectively. Here we are deploying line feed method technique for simulation.
\end{abstract}

Keywords: T and Square shaped; IE3D Software, satellite communication; Mobile communication, RADAR communication, U.W.B (Ultra Wide Band).

\section{INTRODUCTION}

The field of wireless technology crave for the antenna which has potential to perform the respected function, hence the U.W.B system attract more attention in industries and research areas [1]. U.W.B has a number of eye catching properties like bandwidth. Microstrip patch antenna plays a distinguished role in the field of wireless communication due to less weight, compact size, and low manufacturing cost [3]. All antennas is sandwich between patch and ground plane. There are number of different dielectric constant which varies according to the material type. The patch segment is made up of Gold or Copper. The ground plane is already considered as infinite. The efficiency of antenna depends on shape, size \& feed point location. T shape patch antenna has more potential but at the same time it has complex structure [3]. It gives better result in U.W.B. Here in this paper we have compared the different property of reference antenna on FR4 material Vs textile antenna \& also provide related reference data $\&$ graph associated with design.

\section{ANTENNA DESIGN}

The proposed model of two different antennas having a perfectly conducting patch, the ground plane with FR4 substrate and the textile substrate are composed. The FR4 \& jeans antenna has same dimensions in $\mathrm{mm}$.the dimensions are compared \& show with the help of following table.

\begin{tabular}{|c|c|c|}
\hline PARAMETERS & FR4 & TEXTILE \\
\hline Resonant frequency & 2.4 & 2.4 \\
\hline Substrate Thickness & 1.6 & 1.6 \\
\hline Dielectric constant & 4.4 & 1.7 \\
\hline Loss Tangent & 0.0013 & 0.025 \\
\hline
\end{tabular}

$\mathrm{W}=\frac{1}{2 f_{\mathrm{r}}} \sqrt{\frac{2}{\mathrm{E}_{\mathrm{T}+1}}}$

(1)

$\mathrm{C}=$ Speed of light $=3 \times 10^{8} \mathrm{~m} / \mathrm{s}$, Effective dielectric constant $=4.4 \& 1.7, \mathrm{fr}=1.857 \mathrm{GHz}$

$$
\text { ref }=\frac{\varepsilon_{r}+1}{2}+\frac{\varepsilon_{r}-1}{2} \sqrt{1+\frac{12 h}{w}}
$$

$\mathrm{h}=1.6 \mathrm{~mm}$, The extension length $\Delta L$

$$
\frac{\Delta L}{h}=0.412 \frac{(\text { Eref }+0.3)\left(0.264+\frac{w}{h}\right)}{(\text { Eref }-0.258)\left(0.8+\frac{w}{h}\right)}
$$

The length of patch antenna is given as;

$$
L=\frac{c}{2 f r \sqrt{\text { Ereff }}}-2 \Delta l
$$

The length and the width of the ground plane

$$
\begin{aligned}
& \mathrm{Lg}=\mathrm{L}+6 \mathrm{~h}=38.84 \mathrm{~mm} \\
& \mathrm{Wg}=\mathrm{W}+6 \mathrm{~h}=47.47 \mathrm{~mm}
\end{aligned}
$$

Revised Manuscript Received on September 10, 2019.

Zeeshan Alam, Bundelkhand Institute of Engineering and Technology, Jhansi, Utter Pradesh, India.

S.K.Sriwas, Bundelkhand Institute of Engineering and Technology, Jhansi, Utter Pradesh, India.

Atul Kumar Dwivedi, Bundelkhand Institute of Engineering and Technology, Jhansi, Utter Pradesh, India.

Yatharth Shankar Misra, Bundelkhand Institute of Engineering and Technology, Jhansi, Utter Pradesh, India. 
The Effect of Different Dielectric Constant on Same Microstrip Patch Antenna Design

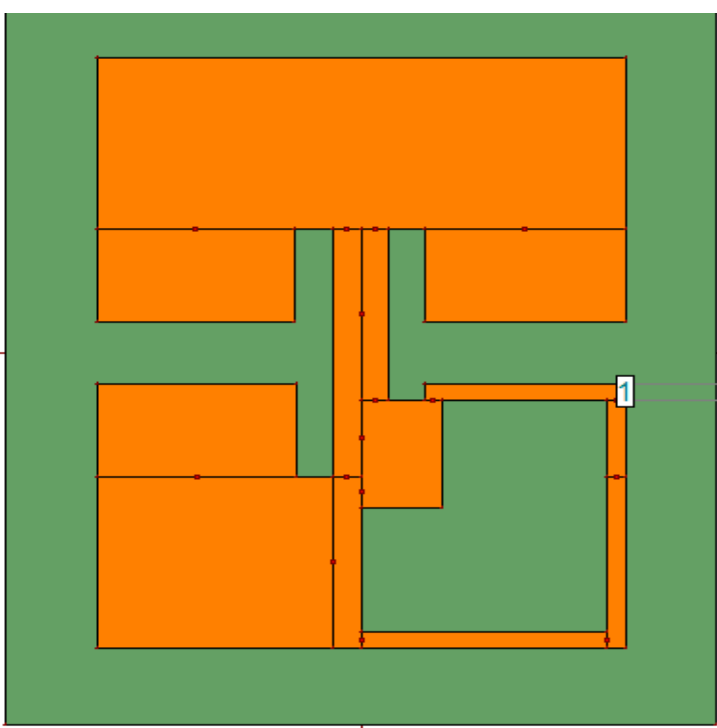

Figure 1: Design of proposed antenna

The above proposed model has patched and ground plane. This design is fabricated using glass epoxy (FR4) as well as textile (jeans), the reason of using FR4 \& Textile materials are

- Easy to available

- Low costing

It has some specific properties like-

- Relative permittivity is of $4.4 \& 1.7$ respectively.

- Loss Tangent is $0.0013 \& 0.025$ respectively.

In this specific design the thickness is of $1.6 \mathrm{~mm}$ for the resonating frequency at $2.4 \mathrm{GHz}$. As in figure 2 , we have cut two " $T$ "' at horizontal and also mirror image of each other. We have already mentioned that we were deploying line feed. The equation (1) to (3) gives the information of width, effective dielectric constant $\&$ length of patch antenna but in this paper we only used $1 / 6^{\text {th }}$ of its part for the betterment of result. The below mentioned table 1 is the result of dimensions that is derived from equation (4)-(5)-(6). As we are already mentioned in our paper, the specific formula used to abstract the information of patch length, patch width, ground length, and ground width respectively.

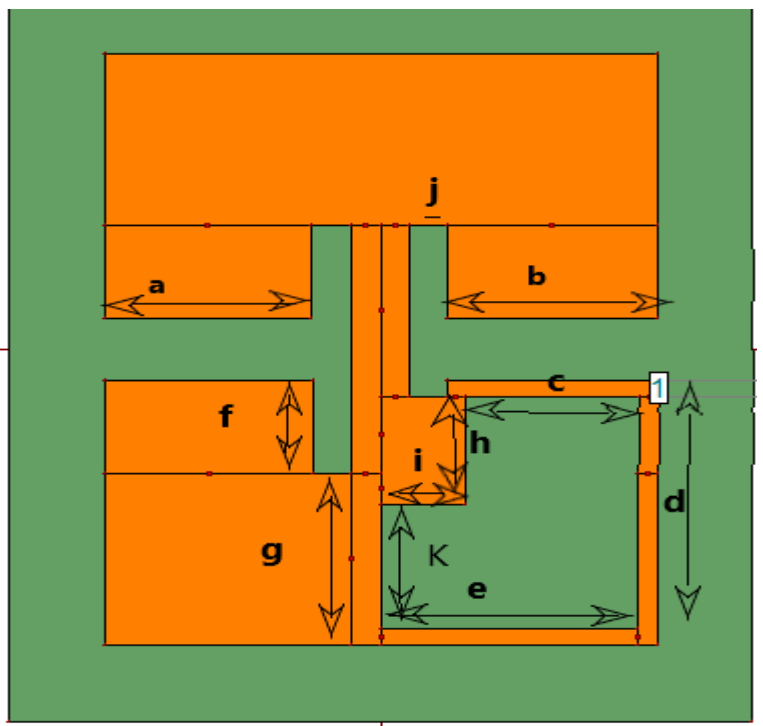

Figure 2: Proposed antenna design
TABLE 1.PARAMETERS AND DIMENTIONS

\begin{tabular}{|c|c|}
\hline PARAMETERS & DIMENTIONS (mm) \\
\hline a & 11 \\
\hline b & 11 \\
\hline c & 9.0 \\
\hline d & 15 \\
\hline e & 13.5 \\
\hline$f$ & 6 \\
\hline $\mathrm{g}$ & 11 \\
\hline $\mathbf{h}$ & 7 \\
\hline $\mathrm{i}$ & 4.5 \\
\hline $\mathrm{j}$ & 2 \\
\hline k & 8 \\
\hline $\mathbf{L}_{\mathrm{g}}$ & 38.84 \\
\hline $\mathbf{W}_{\mathrm{g}}$ & 47.47 \\
\hline $\mathbf{L}_{\mathrm{p}}$ & 29.24 \\
\hline $\mathrm{W}_{\mathrm{p}}$ & 37.87 \\
\hline
\end{tabular}

\section{RESULT AND DISCUSSION}

The results of the design is simulated through IE3D (2015) software, the simulated result includes the following -

- Return loss

- VSWR

- Gain

- Directivity

- Efficiency

The Return loss is a graph of reflection coefficient $(\mathrm{dB}) \mathrm{Vs}$ frequency $(\mathrm{GHz})$.The return loss for the above mentioned patch design is inserted below in Fig(3), Having resonation frequency at $2.9 \mathrm{GHz}, 4.2 \mathrm{GHz}, 5.06 \mathrm{GHz}, 6.30 \mathrm{GHz} \&$ also consist return loss of $-25.26,-18.76,-23,-31.03 \mathrm{~dB}$ respectively. The bandwidth is $103.57 \%$. The lower frequency and upper frequency are $2.7 \mathrm{GHz} \& 8.5 \mathrm{GHz}$ respectively.

Now we change the substrate from FR4 material to textile material \& also inserted a comparison graph in Fig 3. Having resonating frequency at $4.45 \mathrm{GHz}$ and $7.96 \mathrm{GHz}$ and return loss of $-24.76,-20.89 \mathrm{~dB}$ respectively. The bandwidth is expanded to $109 \%$. The lower and upper frequencies are 3.7 , $12.69 \mathrm{GHz}$ respectively. 


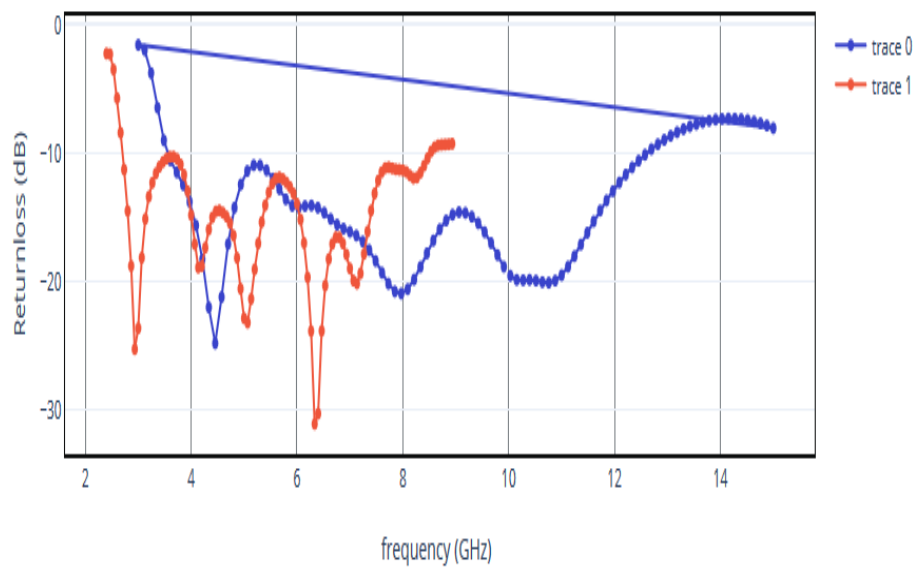

Figure 3: Return loss vs. frequency

VSWR is generally used to graph between Maximum to Minimum voltage, which is stored inside the dielectric. For its maximum efficiency it must lies between the values of 1 to 2.In Fig 4 we have inserted a comparison graph of different dielectric constant (FR4 \& Textile).The table (2) shown below in the "conclusion" section shows that the frequency at which V.S.W.R starts and end. We should always keep in mind that the idol value of V.S.W.R is always lies between 1 to 2 on y-axis.

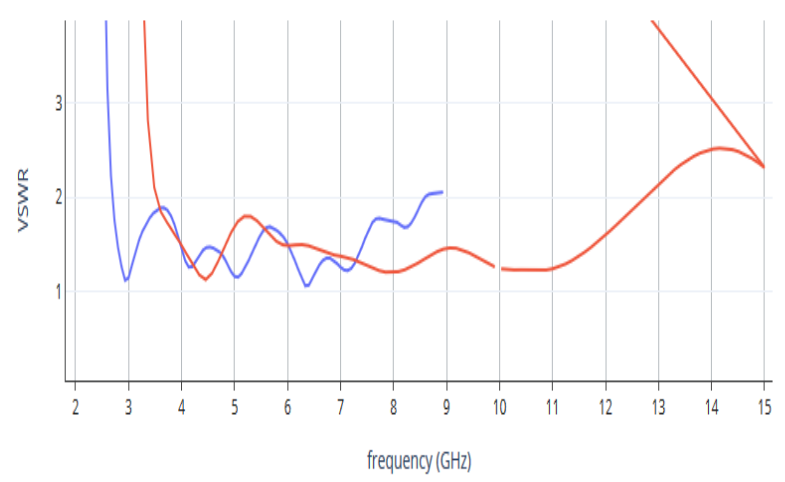

Fig.4 VSWR vs. frequency

Gain plays a major role in antenna that defines the total power radiated in specific direction. The unit of gain is $\mathrm{dBi}$. The way to understand this, It is a logarithmic value of power based on isotropic antenna. In the below given Fig (5) define a relationship between gain and frequency. The graph also shows that it has gain of $7.2 \mathrm{dBi}$, which is quite large. Now if we change the dielectric substrate to Textile the gain is slightly reduced to $6.69 \mathrm{dBi}$.A comparison graph is inserted to support this statement.

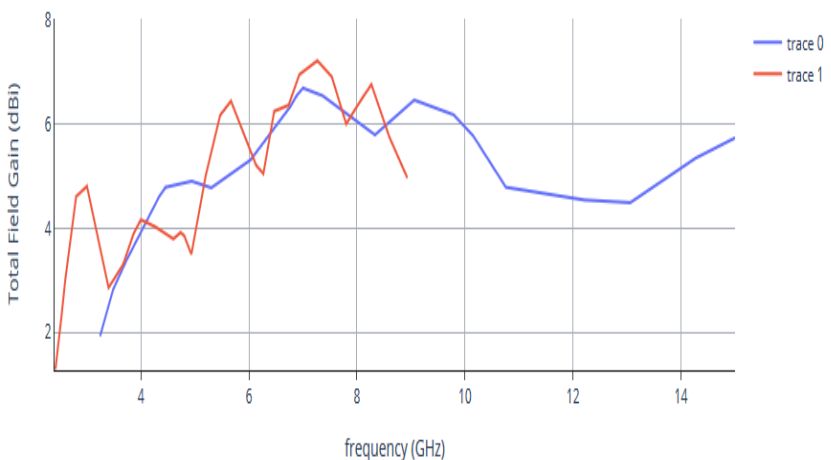

Fig 5: Gain Vs frequency

The term directivity is defining as a fundamental antenna parameter .It help us to calculate how directional of an antenna radiation pattern is. The Fig (6) shows the directivity graph of proposed antenna. The graph shown below shows the directivity of $7.2 \mathrm{dBi}$. The directivity can also be understood as; it is a fundamental antenna parameter.. An antenna that radiates equally in all directions would have effectively zero directionality, and the directivity of this type of antenna would be 1 ( or $0 \mathrm{~dB}$ ). Similarly we change the substrate of dielectric material to textile from FR4 material. The Directivity is also reduced from 7.2 to 6.7dBi.A graph of comparison between FR4 \& Textile material is inserted below to support this analytical statement.

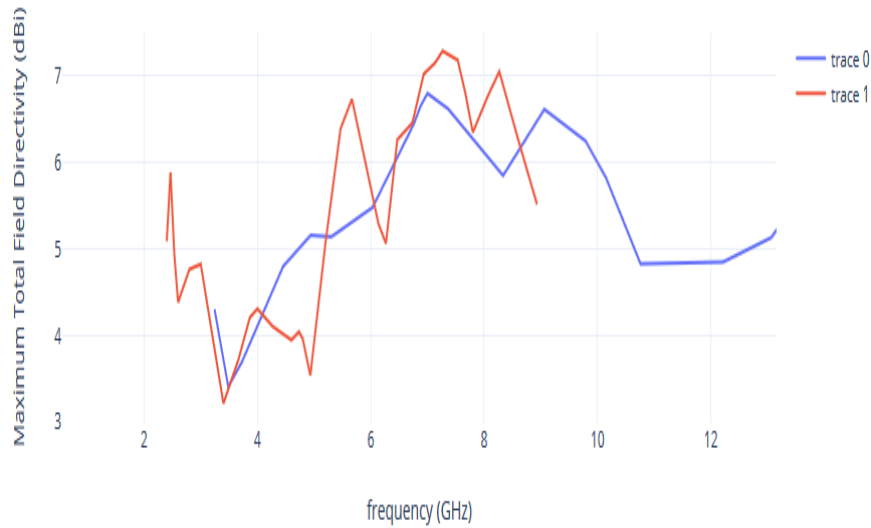

Fig 6: graph of directivity vs. frequency

The efficiency of an antenna is mathematical ratio of the power deployed to the antenna with respect to the power releases from the antenna. A antenna with good efficiency has all of the power present at the antenna's input radiated in a direction or vice - versa due to impedance mismatch. The Fig 7 shows the graph of efficiency of this proposed antenna at different dielectric substance is 99.5 and $99.6 \%$ respectively. The Fig given below support our statement 


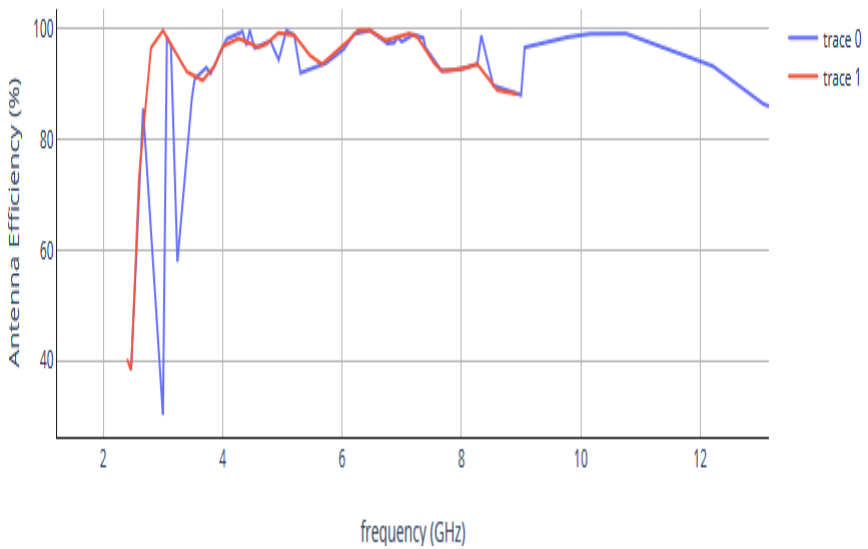

Fig 9: Antenna Efficiency (\%) vs. Frequency (GHz)

\section{CONCLUSION}

The rectangular \& $\mathrm{T}$ shape microstrip patch antenna is fabricated over FR4 and Textile material also simulated for U.W.B applications. As we have seen the return loss covers wide range from $2.7 \mathrm{GHz}$ to $8.5 \mathrm{GHz}$ for (Fr4) and for Textile it covers from 3.7 to $12.69 \mathrm{GHz}$, which covers UWB of 3.6 GHz to $10.6 \mathrm{GHz}$ plus some RADAR frequency. Which are described by FCC Another parameter like Gain, Directivity, and VSWR also came with good performance. we can say it is perfect for U.W.B application. A comparison table is inserted below for detailed analysis of effect to change the substrate.

TABLE 2: COMPARISION OF PARAMETER

\begin{tabular}{|l|l|l|l|}
\hline S.No & parameters & FR4 & Textile \\
\hline 1 & Bandwidth & $103 \%$ & $109 \%$ \\
\hline 2 & VSWR & $\begin{array}{l}2.7 \\
8.5 \mathrm{GHz}\end{array}$ to & 3.7 \\
& & $7.28 \mathrm{dBi}$ & $6.7 \mathrm{dBi}$ \\
\hline 3 & Directivity & $7.21 \mathrm{dBi}$ & $6.69 \mathrm{dBi}$ \\
\hline 4 & Gain & $99.5 \%$ & $99.6 \%$ \\
\hline 5 & Efficiency & \multicolumn{3}{|l}{} \\
\hline
\end{tabular}

So as we can say from the reference of above table parameter like Bandwidth, VSWR, Efficiency has increased with lowering the dielectric constant whereas parameter like directivity and Gain decreases.

\section{Summary-}

This paper helps to understand the design as well as fabrication of the antenna with FR4 and Textile. Textile antennas are constructed over jeans. The copper element work as patch element. From the reference of table listed just above the summary or under conclusion topic we understand that the parameter Bandwidth, VSWR, Efficiency is directly proportion to the Dielectric constant but in the case of Gain and Directivity it is not or in other word it is inversely proportion to Dielectric constant. All the data and analysis is mention in table from in the section of conclusion.

\section{REFERENCES}

1. N. Hojjat, F. G. Kharakhili, M. Fardis, G. Dadashzadeh and A. Ahmadi, "Circular Slot With A Novel Circular Microstrip Open Ended Microstrip Feed For Uwb Applications”, Progress In Electromagnetics Research, PIER 68, 161-167,2007

2. B. J. Kwaha, O. N Inyang\& P. Amalu, "The Circular Microstrip Patch Antenna - Design And Implementation",IJRRAS 8 (1) July 2011

3. W. Mazhar;, M. A. Tarar, F. A. Tahir, Shan Ullah, and F. A. Bhatti, "Compact Microstrip Patch Antenna for Ultra-wideband Applications", PIERS Proceedings, Stockholm, Sweden, Aug. 12\{15, 2013

4. M. Z. M. Nor, S. K. A. Rahim, M. I. Sabran, P. J. Soh, G. A. E. Vandenbosch, "Dual-Band, Switched-Beam,Reconfigurable Antenna for WLAN Applications", IEEE Antennas And Wireless Propagation Letters, Vol. 12,2013.

5. M. Abedian, S. K. A. Rahim, Sh. Danesh, M. Khalily, and S. M. Noghabaei," Ultrawideband Dielectric Resonator Antenna With WLAN Band Rejection at $5.8 \mathrm{GHz}$ ", IEEE ANTENNAS AND WIRELESS PROPAGATION LETTERS, VOL. 12,2013.

\section{AUTHORS PROFILE}

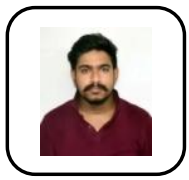

ZEESHAN ALAM have persuaded my Bachelor of technology from Integral University (Lucknow), Utter Pradesh, India in 2016. I am currently pursuing my Master of Technology from bundelkhand Institute of Engineering and Technology (Jhansi), Utter Pradesh, India in 2019.I have published two more paper apart from this paper in which one is national and second one is International conference. I am currently pursuing my M.Tech under the guidance of Surendra Kumar Sriwas

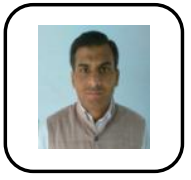

Dr. Surendra Kumar Sriwas received his Bachelor of Engineering in Electronics and communication engineering from Hindustan College of Science and Technology, Mathura (Affiliated to Dr B. R. Ambedkar University Agra, U.P.,India in 2001).He received his M.Tech in Microwave Engineering (Electronics and Communication Engineering) from Madhav Institute of Technology and Science (MITS) Gwalior (Affiliated to RGTU Bhopal, M.P., India) in 2007. He worked as a Senior Lecturer in Electronics and Communication Engineering department, Kanpur Institute of Technology, Kanpur from 4th August 2007 to 5th June 2008 and as a senior lecturer in Electronics and Communication Engineering department, Krishna Institute of Technology, Kanpur from 6th June 2008 to 5th November 2008. He received a Teacher Fellowship by Uttar Pradesh Technical University, Lucknow (U.P.) in December2009 along-with pursuing his Ph.D. research work. He had worked as Teacher-Fellow in Electronics Engineering department, H.B.T.I., Kanpur since16th November 2008 to 15 th December 2009 . He is actively working as Assistant Professor in Electronics \& Communication Engineering department, Bundelkhand Institute of Engineering and Technology (BIET), Jhansi, India. His interests are in Multiple Access Schemes for Optical Channel, Coding Theory, Electronics Engineering, Electronic Circuits and microwave engineering. He has published more than seventeen research papers in different Renault international journals and conference proceedings including the publications from present $\mathrm{PhD}$ research work.

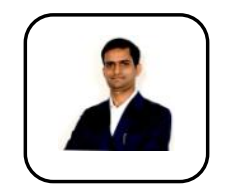

Dr. Atul Kumar Dwivedi persuade his $\mathrm{Ph}$. D. in the specialization of Signal processing and M. Tech. in VLSI Design from NIT Raipur and VNIT Nagpur, India respectively. He is worked on multidimensional digital filter design using FPGA. He is currently worked as Assistant Professor in the department of B.I.E.T (E.C.E) department.

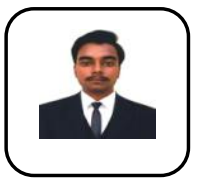

YATHARTH SHANKAR MISRA has done his Bachelor of technology from Bhabha Institute of Technology Utter Pradesh, India in 2016. He is currently pursuing his Master of Technology from Bundelkhand Institute of Engineering and Technology (Jhansi), Utter Pradesh, India in 2019. He have published two more paper apart from this paper in which one is national and second one is International conference. 